\title{
A multilayer thick-film PZT actuator for MEMs applications
}

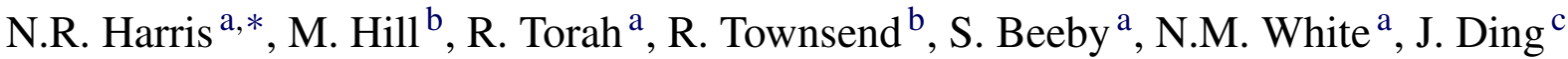 \\ a School of Electronics and Computer Science, University of Southampton, UK \\ ${ }^{\mathrm{b}}$ School of Engineering Sciences, University of Southampton, UK \\ ${ }^{\mathrm{c}}$ School of Mechatronics Engineering, University of Electronic Science \& Technology, Chengdu, China
}

Received 15 September 2005; accepted 29 March 2006

Available online 17 July 2006

\begin{abstract}
This paper describes a technique for replacing the conventional bonded bulk PZT transducer, commonly used in MEMS devices, with a screen printed equivalent. Previously, the piezoelectric activity available from screen printed PZT has been considerably lower than the bulk material, but recent developments in material composition and device structure have allowed screen printed structures to deliver powers equivalent to bulk devices. An actuator using the multilayer screen printed technique was designed for use in an ultrasonic flow-through separator, and its successful use is reported.
\end{abstract}

(C) 2006 Elsevier B.V. All rights reserved.

Keywords: Ultrasonic; MEMS; Thick-film; Separator; Actuator

\section{Introduction}

The conventional method for actuating microengineered structures using PZT has been to use bulk PZT bonded to the structure in question. Such a technique, although effective, is time and labour intensive, as it requires careful alignment and in addition requires significant effort to create repeatable adhesive layers. This can be important beyond the obvious quality of adhesive bond, because ultrasonic transducers in particular have their performance affected by the mechanical properties of the adhesive layer. Work at the University of Southampton has been progressing to develop an alternative to bonded bulk PZT for silicon MEMS actuators by utilizing thick-film processing. Thick-film deposition represents a convenient way of depositing active materials, and developments in processing [1] and paste formulation [2] have allowed the technology to be migrated to silicon. It gives several advantages over bonding bulk material in that it is inherently a batch process, so an entire wafer of devices can be printed in one go. It also gives good repeatability as no bonding layer is required. This work describes an exten-

\footnotetext{
* Corresponding author at: ESD Group, Mountbatten Building, Department of Electronics and Computer Science, University of Southampton, Highfield, Southampton SO17 1BJ, UK. Tel.: +44 2380593274.

E-mail address: nrh@ecs.soton.ac.uk (N.R. Harris).
}

sion of this processing, allowing piezoelectric coefficients to be achieved that are comparable to bulk PZT. The results from this development were used to design a thick-film actuator to drive a microengineered ultrasonic acoustic separator, previously tested using a bulk element [3], and results are reported for this new device, demonstrating the usefulness of the technique.

\section{Description of actuator}

The actuating mechanism is manufactured by co-firing several layers of PZT at $890^{\circ} \mathrm{C}$ each separated by a gold electrode layer, onto a suitable substrate, such as alumina, stainless steel or silicon. Co-firing is a technique whereby multiple layers are printed and dried before being fired once as a complete structure. Conventionally each layer in a thick-film structure is fired individually, but for devices containing PZT, each successive firing results in lead evaporation, altering the chemical composition away from the stoichiometric optimum and leading to a reduction in piezoelectric activity [1]. Evidence of this can be seen in Fig. 3, where the value of $d_{33}$ for a co-fired two-layer structure is higher than that of an individually fired two-layer structure. For evaluation, the multilayer structures were first printed on $630 \mu \mathrm{m}$ thick $96 \%$ alumina tiles. Several test devices were constructed, these consisting of either 1, 2 or 3 PZT layers. The optimum process and multilayer structure was then applied to a 
micromachined silicon wafer, $525 \mu \mathrm{m}$ thick for use in the ultrasonic separator. The printed thicknesses of the PZT layers were measured at around $80 \mu \mathrm{m}$ (Fig. 9). The firing profile used was a standard thick-film cermet profile, with a peak temperature of $890^{\circ} \mathrm{C}$, held for $15 \mathrm{~min}$. The PZT paste is formulated within the Research Group [2]. The structure requires polarization after firing, and this was achieved by applying a $4 \mathrm{MV} / \mathrm{m}$ field at $150{ }^{\circ} \mathrm{C}$ for $30 \mathrm{~min}$ across each layer in parallel, before allowing the structure to cool with the field still applied.

In addition, a device using a bulk PZT drive element, glued to the substrate, was constructed to allow a comparison.

\section{Advantages of a multilayer structure}

The main advantage in producing a multilayered structure is that it enables larger displacements to be generated than would be possible with a single layer having the same total thickness, for a given actuating voltage. In addition, layering the structure allows lower absolute voltages to generate the required polarising field strength. Fig. 1 shows how a two-layer structure is connected and polarised. In the diagram, two layers of $80 \mu \mathrm{m}$ PZT are shown. By linking the top and bottom electrodes, and then applying the polarising field, the two layers are polarised as shown in Fig. 1. In this example, the polarising voltage would be $320 \mathrm{~V}$. If a single $160 \mu \mathrm{m}$ thickness of PZT was used, then the polarising voltage would have to double to $640 \mathrm{~V}$ to give the same field strength. However, the real advantage of the multilayer structure becomes apparent when the structure is used

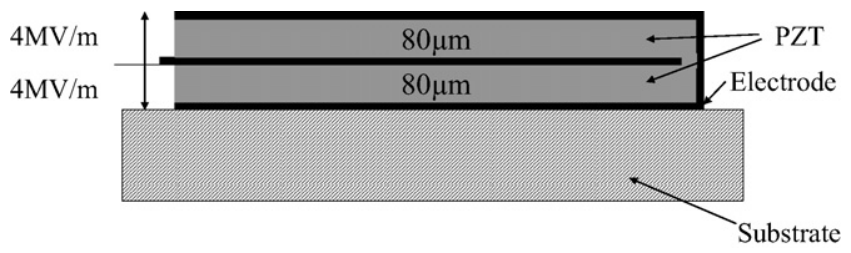

Fig. 1. Structure and polarisation of a two-layer structure.

Displacement $=\mathrm{d}(\mathrm{m} / \mathrm{V}) \times 80 \mu \mathrm{m} \quad \times \mathrm{Va} / 80 \mu \mathrm{m}(\mathrm{V} / \mathrm{m}) / \mathrm{m} \times 2$ layers $=2 \cdot \mathrm{d} . \mathrm{Va}$

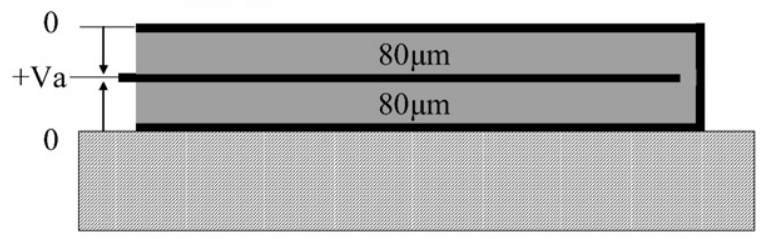

Displacement $=\mathrm{d}(\mathrm{m} / \mathrm{V}) \times 160 \mu \mathrm{m} \times \mathrm{Va} / 160 \mu \mathrm{m}(\mathrm{V} / \mathrm{m})$ $=\mathrm{d} . \mathrm{Va}$

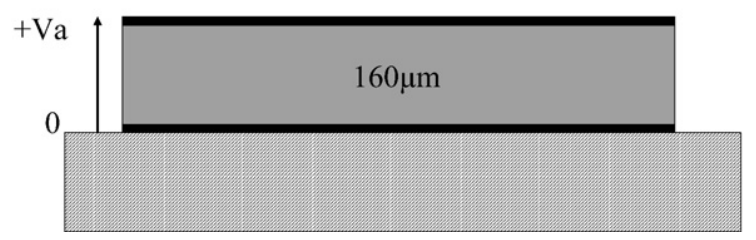

Fig. 2. Comparison of displacement for a one-layer and a two-layer structure. Va is the applied voltage. as an actuator. It can be seen that for a given applied voltage there is twice the movement as for one layer of an equivalent total thickness. This is an effective increase in the $d_{33}$ coefficient of $100 \%$, although care must be taken in the definition of $d_{33}$ in this application. We are using it as a relative measure of the piezoelectric activity of these structures, as by the nature of their construction they are clamped along one edge.

This increase in effective piezoelectric activity comes about because twice the actual voltage is being applied as compared with a single double thickness layer (Fig. 2). This means that, when compared with an equivalent total thickness single layer, the multilayer devices can be driven at a lower voltage to give the same displacement.

A three-layer structure is polarised in a similar way and in principle gives three times the movement than for one layer. It is possible to keep increasing the number of layers in this way but in practice it has been found that the current sensible limitation is three layers.

\section{Test results}

$d_{33}$ coefficients were measured using a Take Control PM35 piezometer. The results, given in Fig. 3, show the expected increase in $d$ coefficient, although the results appear to show that the improvement is not a straight multiplication. For example, the triple layer results are approximately four times the single-layer results, whereas simple theory would predict three times. The reasons for this are not apparent at present, and more results are required to determine whether this is due to process variations or a fundamental effect. Possible causes include less PZT being degraded during the firing process, or the additional layers being further removed from the surface of the substrate and so experiencing less clamping. In order to test the devices' usefulness for driving sound into water, an experimental process was devised to allow the transducer efficiency to be calculated. Direct measurements of acoustic output power were available from an acoustic force balance. This instrument measures the acoustic force from a water loaded transducer. It is also necessary to measure the input electrical power dissipated in the transducer under these conditions. This is available through impedance measurements of the transducer. To prepare the devices for these measurements, a layer of waterproof conformal coating was sprayed on to seal the devices against

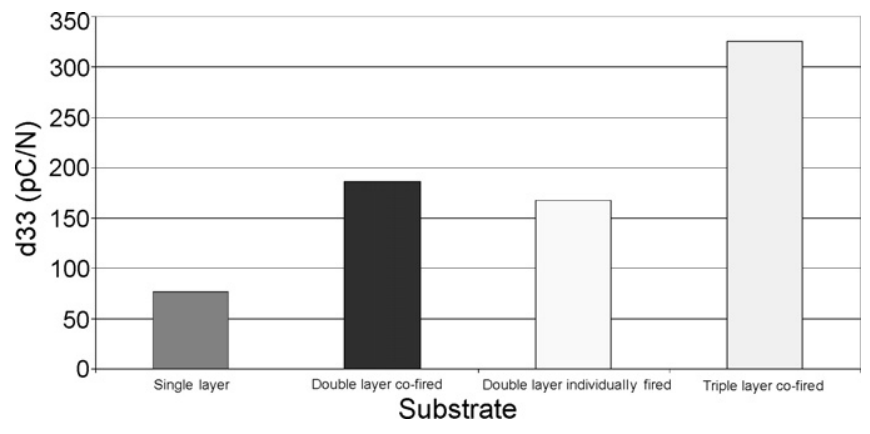

Fig. 3. Piezoelectric coefficient results. 
Table 1

A comparison of results for different devices

\begin{tabular}{llll}
\hline Type & $\begin{array}{l}d_{33} \text { typical } \\
(\mathrm{pC} / \mathrm{N})\end{array}$ & $\begin{array}{l}\text { Resonant } \\
\text { frequency }(\mathrm{MHz})\end{array}$ & $\begin{array}{l}\text { Efficiency } \\
(\%)\end{array}$ \\
\hline Bulk & 246 & 3.4 & 18 \\
One layer & 81 & 5.7 & 36 \\
Two layer & 178 & 4.9 & 43 \\
Three layer & 323 & 3.9 & 35 \\
\hline
\end{tabular}

water ingress before impedance and power measurements were taken.

\subsection{Impedance measurements}

The devices were mounted in a frame to allow ease of handling, and mounted face down in a beaker of degassed water. Impedance measurements were taken using a HP 4192A LF impedance analyser. These measurements enabled the transducer resonance frequency to be identified, and it was noted that this varied with the number of layers in a repeatable manner (Table 1).

\subsection{Acoustic power measurements and electrical power calculations}

An acoustic force balance (Ohmic Instruments UPM-DT-1) was used to directly measure the acoustic output power of the devices. These were then compared with the calculated power input to the device. The system used to calculate the input power is shown in Fig. 4, where $Z$ denotes the impedance of the transducer. The amplifier gave a fixed $50 \mathrm{~dB}$ amplification and had an output impedance of $50 \Omega$. The signal generator was set to $250 \mathrm{mV}$ peak to peak output $\left(V_{\mathrm{GEN}}\right)$, which gave a driving voltage $\left(V_{\text {AMP }}\right)$ from the amplifier of $27.9 \mathrm{~V} \mathrm{RMS}$. This was chosen to give a good acoustic output signal without overstressing the transducer. The $50 \Omega$ output impedance of the amplifier forms a potential divider with the transducer $Z$. The impedance of the load $Z$ was measured using a Hewlett Packard 4192A LF impedance analyser across a range of frequencies.

This allowed the power delivered to the load to be calculated. Power dissipated in the load is given by

Power $=\operatorname{Re}\left\{V_{\mathrm{OUT}} I^{*}\right\}$

where $V_{\text {OUT }}$ is the voltage across the load and $I$ is the current through the load. Now we can calculate $V_{\text {OUT }}$ from the potential

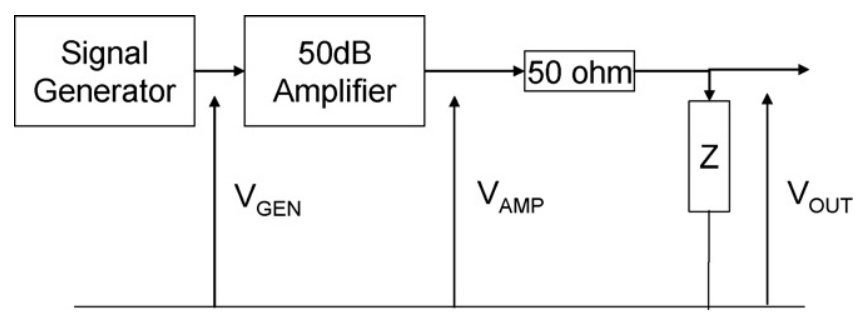

Fig. 4. Experimental system.
Bulk PZT

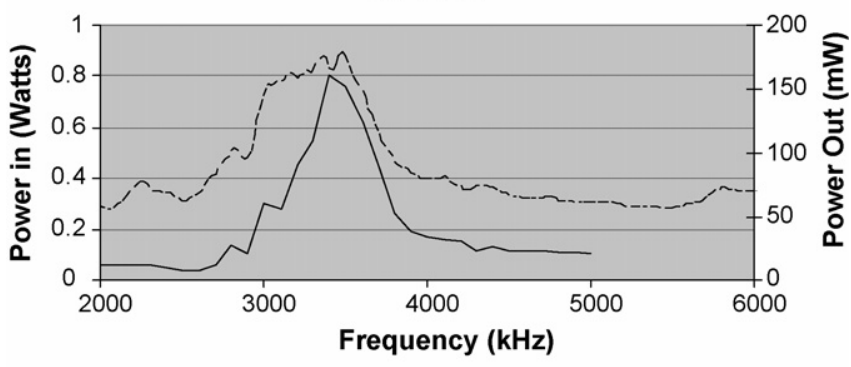

Power In - Acoustic Power

Fig. 5. Power measurements for a bulk PZT drive element.

divider formed by the load and the amplifier output impedance:

$V_{\mathrm{OUT}}=V_{\mathrm{AMP}}\left(\frac{Z}{Z+50}\right)$

as we know that $V_{\text {AMP }}$ is fixed and we have measured $Z$.

Now $I=V_{\text {OUT }} / Z$ from Ohms Law, and therefore power dissipated can be calculated as

$$
\begin{aligned}
\text { Power } & =\operatorname{Re}\left\{V_{\text {OUT }}\left(\frac{V_{\text {OUT }}}{Z}\right)^{*}\right\}=\operatorname{Re}\left\{\frac{\left|V_{\text {OUT }}\right|^{2}}{Z^{*}}\right\} \\
& =\left|V_{\text {OUT }}\right|^{2} \operatorname{Re}\left\{\frac{1}{Z^{*}}\right\}
\end{aligned}
$$

The powers calculated can then be compared with the directly measured acoustic powers to give a measure of the transducers' efficiency (Table 1).

This procedure was carried out for the 1, 2 and 3 layer samples, as well as a bulk sample. An example trace for the bulk sample and a two-layer sample are given in Figs. 5 and 6, showing both the direct acoustic power output measurements and the calculated input powers to the devices. The test devices have shown themselves to be more efficient at converting electrical energy into acoustic energy transmitted into water [5], than the equivalent bulk device (Figs. 5 and 6), and it was concluded that a two-layer device would prove suitable for the separator application. Although a three-layer device is possible, there were yield problems with these devices, and the data suggested a two-layer device would perform at least as well as the bulk device.

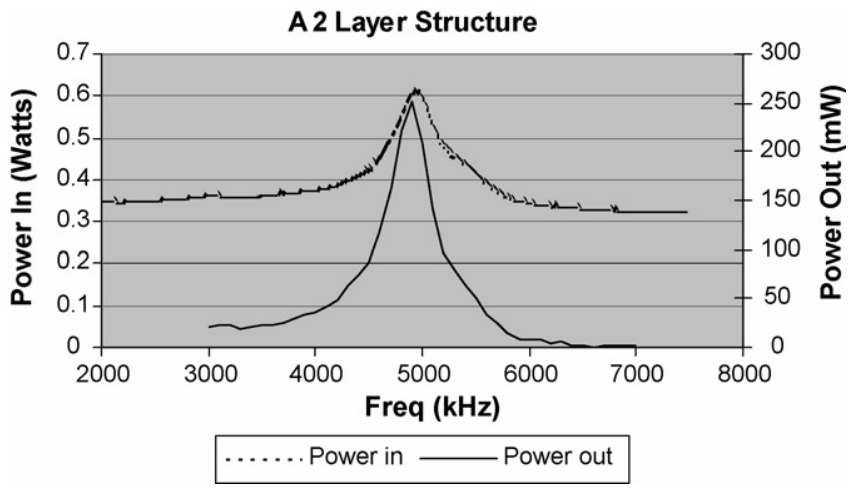

Fig. 6. Power measurements for a two-layer thick-film structure. 


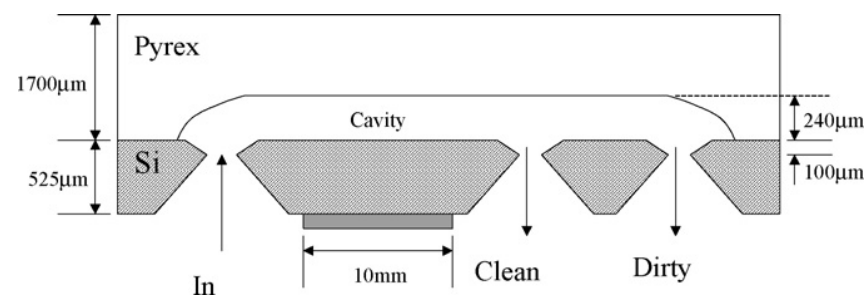

Fig. 7. Cross-section of an ultrasonic separator.

\section{Ultrasonic separator}

The principle of operation of the separator is given in Ref. [3], but in brief, the actuator is used to establish an acoustic standing wave within the cavity, and particles within the fluid are driven to the nodes by radiation forces. Fig. 7 shows a crosssection of a typical device. In this device, we are working with a half-wave cavity and so particles will be driven towards a nodal plane in the centre of the cavity, although it is possible to design for a quarter wave cavity, where particles are driven to the Pyrex wall [7]. In the half-wave case discussed here, by adjusting the relative flows at the two outlets, a 'clean' and a 'dirty' flow can be extracted.

\section{Separator construction}

A wafer of devices was fabricated and a two-layer thick-film actuator was deposited on the silicon in place of the bulk PZT. The silicon wafer was a standard $525 \mu \mathrm{m}$ wafer, etched with access ports as indicated in Fig. 7, and an etched Pyrex wafer was anodically bonded to this wafer to create the device. A twolayer actuator was printed with gold electrodes, and polarised, as described earlier. A sample device was sliced longitudinally and is shown in Fig. 8. This picture shows (from right to left) the two PZT layers and the gold layers of the actuator, the silicon carrier layer, the fluid gap and finally the Pyrex backing layer, and gives a good indication of the relative scales of the different layers.

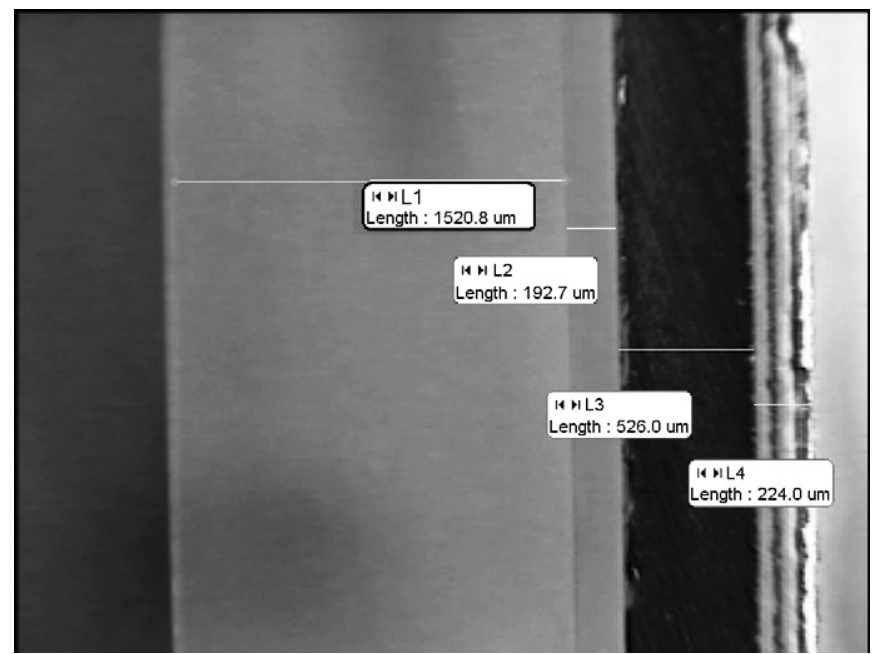

Fig. 8. A cross-section of a device.

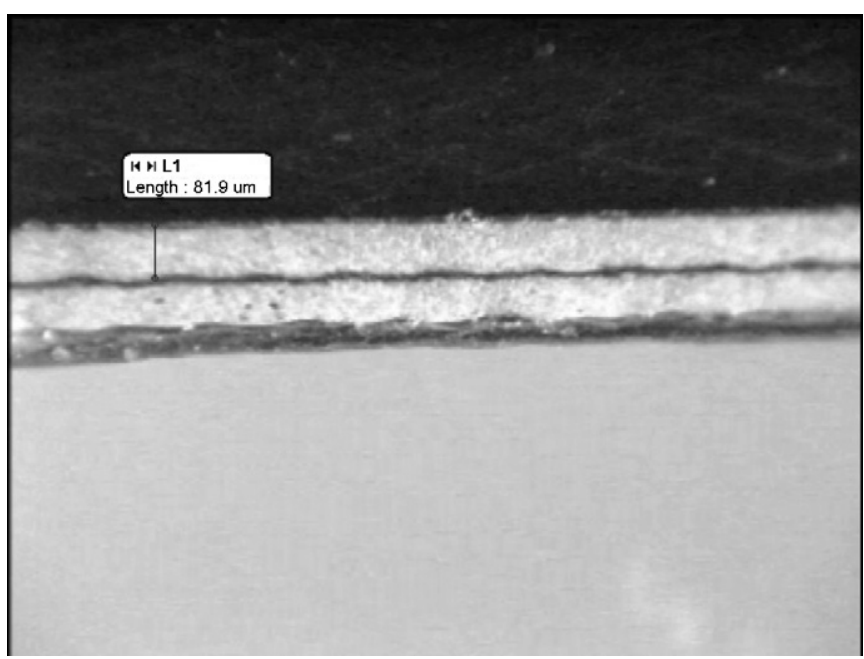

Fig. 9. Detail of the PZT layers.

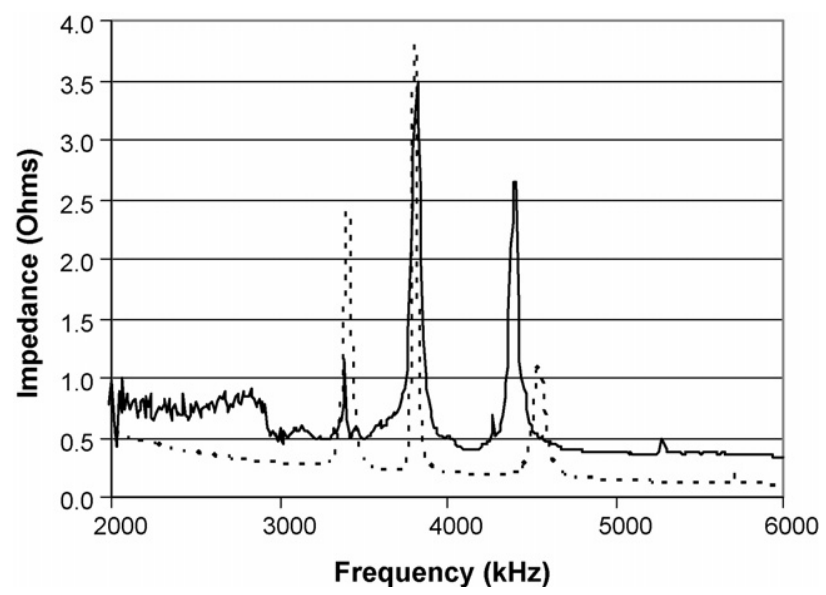

Fig. 10. Real part of impedance (solid-measured, dotted-modelled)

Fig. 9 shows a more detailed photograph of the thick-film layer. A good uniformity of printing is apparent, with the PZT layer being about $82 \mu \mathrm{m}$ thick. The gold electrode layers are also visible, with no signs of migration through the layers. Impedance measurements indicated that the composite structure has a resonance of about $3.9 \mathrm{MHz}$ in air. When filled with water, impedance measurements show that the two predicted half-wave modes were present, indicating that the model should give a good indication of the performance of the device (Fig. 10). The device was operated at the peak at $4.4 \mathrm{MHz}$.

\section{Separator test}

The experimental procedure was as described in [6], in that turbidity measurements were taken using a Honeywell APMS-10GRCF turbidity sensor, previously calibrated against a haemocytometer for the latex particles used, and the pumping arrangement was as shown schematically in Fig. 11.

The total flow rate through the device was $5.1 \mu \mathrm{l} / \mathrm{min}$ with a flow rate split between the outlets of $75 \% / 25 \%$ between outlets 1 and 2 as shown in Fig. 11. The device is isolated from the pulses produced by the pumps by using air filled syringes to act as 


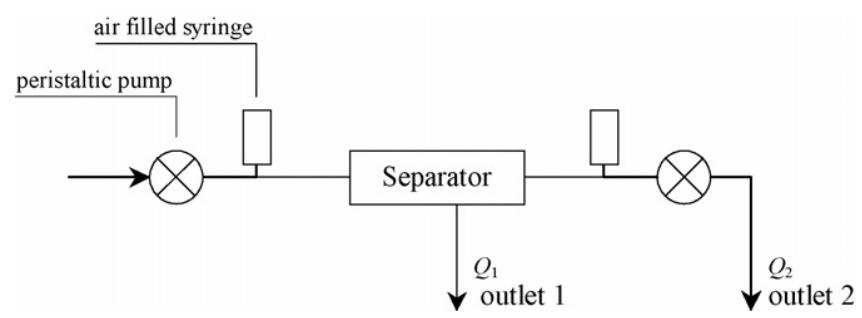

Fig. 11. Schematic of experimental arrangement.

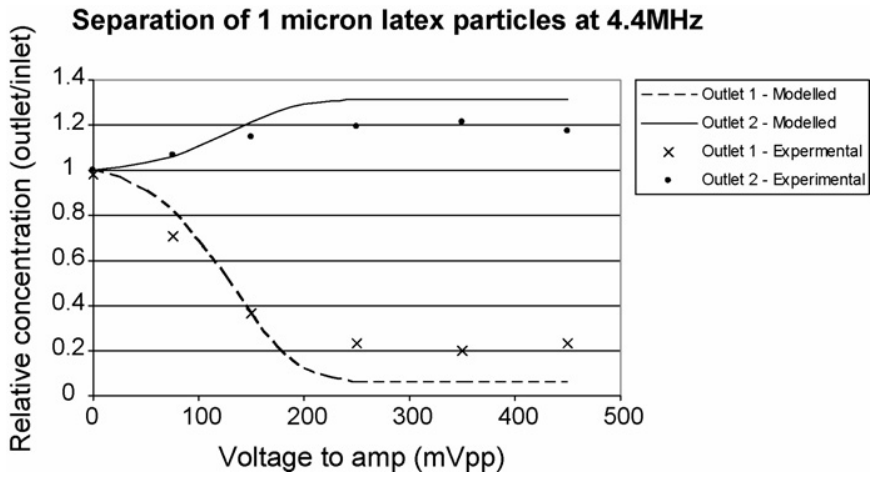

Fig. 12. Performance of a thick-film actuated separator.

dampers. The performance of the separator running at $4.4 \mathrm{MHz}$ was measured at different drive voltage levels, and the measured results are plotted in Fig. 12. This figure shows the variation in particle concentration of the two outlets flows, with separation improving at the higher voltage levels. It can be seen that these measured results compare favourably with the predicted results [4] thus verifying the predictions of the model, and demonstrating the usefulness of the thick-film PZT multilayer actuator in this application.

\section{Conclusions}

The results show that the thick-film PZT actuator performs well as an acoustic source in this application, and further that the previously developed model for predicting the performance of bulk PZT driven concentrators has been verified for thick-film PZT actuators. In addition, it can be concluded that thick-film actuators are more efficient than bonded bulk PZT actuators for this application. We therefore conclude that thick-film multilayer actuators are a viable alternative to bonded bulk PZT actuators on silicon, with the added advantage of being batch processable on a wafer scale.

\section{Acknowledgements}

The authors wish to thank the Engineering and Physical Research Council (EPSRC) for their financial support under grant number GR/R13333/01, and acknowledge the financial support given by DSTL and Porvair Filtration Group. Special thanks are due to Angela Cotton in the Medical Physics department at Southampton General Hospital for the use of the power balance.

\section{References}

[1] R. Maas, M. Koch, N.R. Harris, N.M. White, A.G.R. Evans, Thick-film printing of PZT onto silicon, Mater. Lett. 31 (1997) 109-112.

[2] R.N. Torah, S.P. Beeby, N.M. White, Improving the piezoelectric properties of thick-film PZT: the influence of paste composition, powder milling process and electrode material, Sens. Actuators A 110 (2004) 378-384.

[3] N.R. Harris, M. Hill, R. Townsend, N.M. White, S.P. Beeby, Performance of a micro-engineered ultrasonic particle manipulator, in: Proceedings of the Eurosensors XVIII, Rome, September 12-15, 2004, pp. 203-204.

[4] R.J. Townsend, M. Hill, N.R. Harris, N.M. White, Modelling of particle paths passing through an ultrasonic standing wave, Ultrasonics 42 (2004) 319-324.

[5] N.R. Harris, R.N. Torah, N.M. White, M. Hill, S.P. Beeby, A PZT multilayer actuator for ultrasonic applications, in: Proceedings of the 15th MicroMechanics Workshop, Leuven, Belgium, 5-7 September, 2004, pp. 17-20.

[6] N.R. Harris, M. Hill, R. Townsend, N.M. White, S.P. Beeby, Performance of a micro-engineered ultrasonic particle manipulator, Sens. Actuators B 111 (2005) 481-486.

[7] N.R. Harris, M. Hill, Y. Shen, R.J. Townsend, S. Beeby, N. White, A dual frequency, ultrasonic microengineered particle manipulator, Ultrasonics 42 (2004) 139-144.

\section{Biographies}

Nick Harris is a lecturer based in the electronics and computer science department at Southampton. He graduated in 1988 from the University of Bath and was awarded a PhD in 1997 from the University of Southampton, on the use of ultrasound for communication purposes. His research interests include thickfilm sensors and surface acoustic wave devices, microengineering, and sensor interfacing. He is a member of the IEE and a Chartered Engineer.

Martyn Hill is a reader in Electromechanical Systems in the School of Engineering Sciences, Southampton University. He graduated in 1985 from the Institute of Sound and Vibration Research, was appointed lecturer in 1990 and has research interests in acoustics (particularly ultrasonics) and transducers. His work has led to more than 80 publications, he is a chartered engineer, a member of the Institute of Measurement and Control, and a member of the Institute of Acoustics.

Russel Torah obtained his degree of BEng (Hons) in electronics engineering in 1999 and an MSc in instrumentation and transducers in 2000 at the University of Southampton. After completing his $\mathrm{PhD}$ on the optimisation of piezoelectric properties in thick-film PZT ceramics, he was appointed as a research fellow within the Electronic Systems Design Group at the University of Southampton, and has research interests in thick-film technology and MEMS devices.

Rosemary Townsend graduated in 2000 from the University of Southampton with an MEng in mechanical engineering and is now studying for a $\mathrm{PhD}$ within the Electro-mechanical Research Group at Southampton. Her work involves the numerical simulation of particles under the influence of acoustic forces and other aspects of microfluidic device simulation. She is an associate member of the IMechE.

Steve Beeby graduated from the University of Portsmouth in 1992 with BEng (Hons) in Mechanical Engineering. He obtained a PhD from the University of Southampton in 1998. He is currently an EPSRC Advanced Research Fellow researching active thick-film material developments and their combination with micromachined devices. His other research interests include energy harvesting for remote wireless sensor networks. He is also interested in human biometric systems. He has over 90 publications in the field. He is co-author of a recently completed book entitled 'MEMS Mechanical Sensors' published by Artech House. He is a Chartered Engineer and Chartered Physicist.

Neil M. White is a professor of intelligent sensor systems within the School of Electronics and Computer Science at the University of Southampton and also director of the Institute of Transducer Technology. He was awarded a PhD in 1988 for a thesis on the application of thick-film piezoresistors for load cells. $\mathrm{He}$ has published extensively in the area of thick-film sensors and intelligent instrumentation and is author or co-author of over 100 scientific publications. He 
is a fellow of the Institute of Physics, a chartered engineer and a senior member of the IEEE and has served of several committees in various professional bodies.

Jiexiong Ding was awarded a Bachelor's degree in Mechanical Engineering from the University of Electronic Science and Technology, Chengdu in 1987. After a period in industry he returned to complete a Masters in Mechatronics and was appointed as a lecturer in Chengdu in 1992. He is now Professor of Mechatronics and Vice-Dean of the School of Mechatronics Engineering, and has research interests in Mechatronics and Precision Engineering. 